Revista de la red interuniversitaria de estudios sobre las literaturas rioplatenses contemporáneas en Francia

8 | 2013

Argentina y Uruguay: lecturas del país vecino en la literatura rioplatense contemporánea (siglos XX y XXI)

\title{
Narrar al sesgo: diálogos entre dos orillas en torno al horror
}

Ana María Amar Sánchez

\section{OpenEdition}

1 Journals

Edición electrónica

URL: http://journals.openedition.org/lirico/890

DOI: $10.4000 /$ lirico.890

ISSN: 2262-8339

Editor

Réseau interuniversitaire d'étude des littératures contemporaines du Río de la Plata

Referencia electrónica

Ana María Amar Sánchez, "Narrar al sesgo: diálogos entre dos orillas en torno al horror », Cuadernos LIRICO [En línea], 8 | 2013, Puesto en línea el 01 enero 2013, consultado el 19 abril 2019. URL : http:// journals.openedition.org/lirico/890; DOI : 10.4000/lirico.890

Este documento fue generado automáticamente el 19 abril 2019.

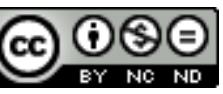

Cuadernos LIRICO está distribuido bajo una Licencia Creative Commons Atribución-NoComercialSinDerivar 4.0 Internacional. 


\title{
Narrar al sesgo: diálogos entre dos orillas en torno al horror
}

\author{
Ana María Amar Sánchez
}

1 En el cuento de Borges « Deutsches réquiem », un narrador nazi nos pone al tanto de su « larga carrera de maldad» -como diría Hannah Arendt- « ante la que las palabras y el pensamiento se sienten impotentes $»^{1}$. Esta impotencia ante el horror es evidente en la reticencia del personaje editor cuando no puede soportar el relato del campo que el narrador nazi comienza así : « Determiné aplicar ese principio al régimen disciplinario de nuestra casa y... » El editor interrumpe la descripción, incluye tres puntos suspensivos y aclara en la nota al pie : «Ha sido inevitable, aquí, omitir unas líneas » ${ }^{2}$. El relato expone así uno de los problemas centrales en torno a la narración de los episodios relativos al nazismo : la dificultad para abordar los implícitos límites de estas representaciones; esta dificultad plantea dilemas no sólo estéticos, sino también éticos. De hecho, numerosos trabajos parecen coincidir -como señala Friedlander en el prólogo a su antología En torno a los límites de la representación- en que « hay límites para la representación que no deben ni pueden ser fácilmente transgredidos $»^{3}$. La naturaleza de esa transgresión está, por supuesto, lejos de ser un punto de coincidencia entre los distintos autores ${ }^{4}$.

2 Creo que la diversidad de interpretaciones del cuento borgeano se origina, justamente, en lo que es su gran acierto: el modo de representar. Borges ha establecido una distancia entre el suceso traumático y la escritura; evita así la trampa de la identificación emocional sostenida por las imágenes de la violencia y el horror nazi destinadas a sacudir la sensibilidad del receptor. Se inclina, por el contrario, por una concepción que recuerda el distanciamiento brechtiano, opuesta a un proyecto catártico frecuente en los relatos cinematográficos hollywoodenses, destinados a «una fácil pero ineficiente solución crítica », según dice el crítico español Gómez López-Quiñones ${ }^{5}$.

El mismo reparo que domina al editor en el cuento de Borges lo opone al narrador nazi y genera un espacio que yo llamaría una ética de la escritura -una ética del relato. Es decir, el cuento pone en acción interesantes mecanismos en tanto tiene como narrador a un asesino despreciable y, sin embargo, la posición ética de la escritura -del cuento- está en las antípodas de ese personaje. Es quizá debido a esto que el relato de Borges ha sido 
frecuentemente mal leído y mal interpretado. Sin duda, la figura del editor es fundamental en tanto quiebra la confesión del narrador con sus comentarios, interpreta y se niega a reproducir lo que suponemos las descripciones del « régimen disciplinario » del campo. Esta omisión es especialmente significativa porque indica una decisión y toma de partido, no sólo en lo que respecta a aquello que puede o debe ser contado, sino que es índice de la repugnancia que le provoca el relato de las atrocidades cometidas.

El contrapunto entre los comentarios del editor y la información del narrador va construyendo una evaluación ética de los acontecimientos que se completa con las declaraciones explícitas de Borges en la nota final que cierra la colección. De este modo, el relato del nazi se confronta con la nota del autor y ésta, a su vez, lo cuestiona : la frase de Borges « el trágico destino alemán [...] que no supieron llorar, ni siquiera sospechar, nuestros "germanófilos" ${ }^{6}$ da " una vuelta de tuerca » y otorga todo su sentido al cuento, desde una perspectiva bien distinta a la del alemán. Se ha producido así una distancia entre la voz del narrador (quien ha explicitado su « confianza » en el futuro del nazismo y confesado la ausencia de culpa y arrepentimiento) y la « voz » del relato, sostenida por el personaje editor y el autor real, quien firma la nota final e incluye fecha y lugar de su escritura (Buenos Aires, 3 de mayo de 1949). Así, el cuento se transforma en un texto de anticipación de la historia posterior, no sólo argentina. El mensaje del narrador nazi funciona como un testamento victorioso para el futuro: « se cierne ahora sobre el mundo una época implacable. Nosotros la forjamos $»^{7}$. Su objetivo es demostrar el triunfo final de Alemania : "Mañana moriré, pero soy un símbolo de las generaciones del porvenir "8. Cobra así un claro sentido la nota final a la colección en la que Borges habla « del trágico destino alemán » y define al cuento como un intento de entender ese destino\%.

Treinta años después de « Deutsches réquiem », en 1979, en los tiempos en que la profecía del narrador nazi se ha convertido en realidad y tragedia, otro cuento, « Graffiti » de Julio Cortázar, narra el horror y lo hace a través de un relato en que graffitis casi sin palabras sostienen el diálogo de los protagonistas. El cuento fue escrito en homenaje a -y para el catálogo de- una exposición de Antoni Tàpies, el pintor catalán cuyos cuadros expresionistas abstractos, cual grafittis, resaltan la corporalidad misma del material usado constituyendo una fusión de pintura, collage y grafía. En el catálogo dialogan imagen y palabra, Tàpies y Cortázar ; arte y política se funden en una misma estética : el diálogo entre escritura y pintura confluye en la palabra graffiti. En ambos casos, los graffitis valen " por estar ahí », no por representar nada miméticamente; son sólo trazos, huellas que « hablan » sin explicitar. En el cuento, sólo una vez aparece escrita en la pared una frase, «a mí también me duele $»^{10}$, que resume la historia, pero no la describe ni la explica. El relato nos ubica en un tiempo de persecución y peligro por «el toque de queda, la prohibición amenazante de pegar carteles o escribir en los muros $»^{11}$, pero lo mismo que hace el editor del texto de Borges, el narrador omite describir y alude a la tortura oblicuamente: «lo sabías muy bien, te sobraría tiempo para imaginar los detalles de lo que estaría sucediendo en el cuartel general »[el subrayado es mío] ${ }^{12}$. El cuento trabaja exhaustivamente el juego entre ver ( una noche viste su primer dibujo ${ }^{13}$, " viste la lucha $»^{14}$ ), mirar de soslayo ( la gente que le echaba una ojeada al pasar $»^{15}$ ), saber ( «la gente estaba al tanto del destino de los prisioneros $\left.\|^{16}\right)$, imaginar y suponer. Entre lo que se ve, se sabe o se imagina se va construyendo el ámbito de lo que no se puede o quiere ver y saber: los graffitis exponen ese vacío, llenan de trazos el hueco, evocan una ausencia. 
6 La comunicación entre los personajes será a través de esos graffitis prohibidos, tan peligrosos en sus trazos abstractos como para llevar a la muerte y contener, a la vez, la posibilidad de resistencia y memoria como señala la voz narradora en el final : « tenía que decirte adiós y a la vez pedirte que siguieras ${ }^{17}$; en sus líneas y materialidad está también la posibilidad de resistir. Si el grafitti final nos « habla » de tortura y muerte, también nos interpela con su esperanza de continuar. El cuento no ha sido explícito y los graffitis tampoco, pero están ahí, significan por sí mismos, son signos, trazos sesgados, oblicuos, que dicen todo sin decirlo : el hueco en la pared, ese espacio vacío tan caro a Cortázar, se llena de $\operatorname{trazos}^{18}$. La huella de la desaparición ha quedado en el graffiti, por eso no es necesario contar, basta con describir esos dibujos abstractos que son, precisamente, descripciones de cuadros de Tàpies : «tu dibujo [es] una rápida composición abstracta en dos colores $»^{19} \mathrm{o}$ " una noche viste su primer dibujo solo ; lo había hecho con tizas rojas y azules en una puerta de garage, aprovechando la textura de las maderas carcomidas y las cabezas de los clavos $»^{20}$. Como se sabe, en la pintura de Tàpies predominan el negro, los colores oscuros y el rojo vivo sobre texturas rugosas -maderas carcomidas, cartón, arpillera- en las que se han incorporado piedras, clavos y otros materiales; incluye fragmentos de puertas y ventanas e imágenes de muro, usa figuras geométricas como óvalos, triángulos y espirales, mezcla pintura, collage; es decir, sus obras pueden ser asimiladas con frecuencia a graffitis. En su materialidad misma, en los desechos que usan, se proponen como un testimonio político de una época.

7 Del mismo modo, la fragmentaria descripción del momento en que ella, la narradora, desaparece, se duplica en el graffiti que, a su vez, recuerda otro cuadro de Tàpies. El supuesto narrador ve la lucha cuando se la llevan : « un auto dando la vuelta a la esquina $\mathrm{y}$ frenando [...] un pelo negro tironeado por manos enguantadas [...] la visión entrecortada de unos pantalones azules antes de que la tiraran en el carro y se la llevaran » y alcanza a ver también el dibujo que ella dejó en la pared que es « un esbozo azul, los trazos de ese naranja que eran como su nombre o su boca $»^{21}$. Éste se corresponde con el único graffiti que permanece sin borrar : « un grito verde, una roja llamarada [...] un óvalo que era también tu boca y la suya $»^{22}$. La secuencia se cierra con el último, que puede « leerse » como una imagen distorsionada de la tortura: «el óvalo naranja y las manchas violeta de donde parecía saltar una cara tumefacta, un ojo colgando, una boca aplastada a puñetazos » [el subrayado es mío] ${ }^{23}$; ambos dibujos que parecen representar bocas o caras, son en verdad descripciones casi exactas de cuadros abstractos de Tàpies.

8 Sin duda, este último graffiti representa a la mujer desaparecida, es ella. Como el dibujo, ella es borrada y la vemos en las huellas del mismo; los rastros muestran la ausencia, son su marca y su memoria; la boca aplastada sigue «hablando» en la 0 del graffiti. Los dibujos, aún borrados por la pintura blanca de los represores, permanecen; sus huellas, a la manera de un palimpsesto, son testigos de lo ocurrido. De hecho, cuando el hombre vuelve al lugar de donde fue llevada por la policía, ve los rastros de su dibujo : « quedaba lo bastante para comprender que había querido responder a tu triángulo con otra figura, un círculo o acaso una espiral... $»^{24}$. El texto nos interpela y exige nuestra complicidad, nuestra imaginación y nuestra memoria, nos pide que « sigamos », igual que los restos de los dibujos al personaje que mira ${ }^{25}$. El graffiti insiste, es inútil que lo tapen, lo desaparezcan, porque como ya se leía en una frase de Rayuela curiosamente anticipatoria, " allí donde debería haber una despedida hay un dibujo en la pared ${ }^{26}$.

9 Pocos años después, en 1987, cuando los relatos sobre el horror y la violencia vividos comienzan a multiplicarse, el uruguayo Omar Prego Gadea, posiblemente el autor más 
cercano a Cortázar en la narrativa del Cono Sur y el que sin duda más lo ha homenajeado, publica un volumen, Sólo para exiliados, que se abre con un epígrafe de «Las babas del diablo $\aleph^{27}$. La colección, más aún, incluye un cuento en el que Cortázar es protagonista : « Función nocturna ». En él, el epígrafe está tomado de « Segunda vez », relato de Alguien que anda por $a h \imath^{28}$. El diálogo con Cortázar es claro: «Segunda vez » es un relato en donde " nada pasa " y el lector se ve obligado a imaginar la tortura y desaparición por el cruce de dos perspectivas, la de un torturador y la de su futura víctima que nada sospecha ${ }^{29}$. El espanto de lo que le espera vuelve la historia una pura evocación de la violencia futura. Así ocurre en «Función nocturna » : del mismo modo que en "Las babas del diablo » -un cuento que puede ser leído como un manifiesto estético de rechazo a cualquier posibilidad de fidelidad a lo real- las palabras y las imágenes son las huellas de lo que ha pasado o pasará, son el rastro dejado por los hechos; el lector puede "ver », imaginar, aquello que está presente sólo por omisión.

10 La función nocturna que da título al relato de Prego Gadea parece ser en un primer momento la proyección de un documental sobre Cortázar a la que el mismo autor asiste en un regreso al país en plena dictadura. Lo mismo que en " Graffiti », el entorno sólo se menciona por la situación en las calles, los Ford Falcon, los carros celulares, el miedo. De hecho, el comienzo del relato evoca el de «Graffiti » : « la gente pasaba con aire furtivo, rozando las paredes [...] se escuchaba una brusca frenada [...] había una corta lucha [...] empujones y puntapiés [...] después los neumáticos chirriaban en el asfalto y los testigos se dispersaban en silencio $»^{30}$. Sin embargo, la salida en busca de un restaurante luego de la proyección y la paulatina desaparición « inexplicable » de los miembros del grupo, así como la imposibilidad de encontrar un lugar donde comer o refugiarse, vuelve la última parte del cuento una sinécdoque del terror y la indefensión de los personajes. Allí, en la calle, se juega la verdadera función nocturna ; sin embargo, nada es explícito, un lector distraído o desconocedor de la historia podría pensar en el ingreso del cuento en una clave fantástica. Es decir, el fin de la proyección abre el regreso a «otro tiempo", la pantalla se convierte "en un ventanal amenazante $»^{31}$. El afuera es el espacio de la pesadilla, aunque todo se reduce a perderse en un laberinto de calles y desencuentros : la descripción de ese andar va hundiendo en el horror al lector, sin que parezca ocurrir nada : « La calle lucía amenazante, ahora que estaba enteramente vacía [...] casi todas las casas estaban a oscuras, como en una ciudad sitiada o abandonada [...] La calle quedaba envuelta por una espuma rojiza para ensombrecerse bruscamente $»^{32}$. La suma de hechos o, mejor dicho, de indicios inquietantes -el café donde quedó Cortázar que ya está cerrado, el dueño del restaurante « nervioso o asustado » con un delantal que al narrador le parece «manchado de sangre (seguramente salsa de tomate) »"33, la calle en tinieblas que da « la sensación de estar en un callejón sin salida » y produce la " primera punzada de miedo $\|^{34}$, así como el silencio, la desaparición de todos y de todo lo familiar- hacen pensar al narrador que "cuando todo hubiera pasado Julio sería capaz de escribir un cuento con todo esto, que en el fondo no era nada » [el subrayado es mío] ${ }^{35}$. Esa « nada » se cierra con el caminar del narrador « con el miedo pisándo[le] los talones » y aguardando a que ellos « decidieran venir a buscar[lo] a [él] también ${ }^{36}$. El final transforma esa nada en un tiempo y espacio donde ocurrió el horror, nada parece haber pasado en una superficie que esconde la violencia máxima. Como el editor borgeano que prefiere los puntos suspensivos, o los graffitis en el cuento de Cortázar, que en sus dibujos abstractos eluden, omiten lo insoportable a la vez que lo exponen, este relato donde no pasa nada hace presente el espanto de la desaparición por medio de ese «casi juego " paranoico y ese andar desorientado, como en un laberinto, del narrador. No es casual que éste piense en 
un posible cuento de Cortázar en el que narre "la nada», es decir, un relato elusivo, al sesgo, en el que el lector deba imaginar, construir, reponer, todo el terror implícito ${ }^{37}$.

Elvio Gandolfo -quizá el autor a quien mejor le cabe el título de escritor de ambas orillas por ser un intelectual al que difícilmente podría atribuírsele la pertenencia a uno sólo de esos espacios geográficos- publica en 1982 La reina de las nieves aunque el texto que da título al volumen está fechado en febrero de 1977 y esto de por sí evoca en el lector conocedor todo el horror de aquella época. Puede pensarse que es una narración condensadora de muchos rasgos comunes a los textos analizados aquí y de otros también presentes en numerosos autores del Río de la Plata; de hecho, la nouvelle se inscribe, de un modo muy libre, en la tradición del relato policial, género que, quizá como ningún otro, ha permitido contar la historia política latinoamericana de esos años ${ }^{38}$.

El relato de Gandolfo es un homenaje a Onetti y a Los adioses, libro que el protagonista lee entre la admiración y el estupor, pero también está atravesado por los relatos de otro gran autor desaparecido por la dictadura militar ese mismo año '77: Héctor Oesterheld. La reina de las nieves se abre con la búsqueda de una mujer cuyo paradero se ignora; se trata de la hija de un ex patrón del personaje que toma a su cargo la investigación a la manera de un atípico detective, aunque con poco entusiasmo y poca información (sólo tiene una vieja foto) para llevar adelante la tarea ${ }^{39}$. El « detective » viaja entonces a esa « ciudad del litoral » donde vivió hace veinte años, pero donde ahora perdura una niebla que «según parecía llevaba tiempo instalada sobre la ciudad » ${ }^{40}$. La niebla, el frío y la desolación de los espacios casi siempre vacíos y fantasmales escanden el relato y culminan en el capítulo 16 :

La nieve no caía en copos, sino en ráfagas. Se arremolinaba entre los dos edificios, y cubría los bordes de las ventanas [...] sentía el frío mordiéndole la carne a través de las sucesivas capas de ropa.

Una ráfaga violenta le abrió un poco el sobretodo. Sintió un frío tan penetrante que no pudo reprimir un quejido.

El frío seguía siendo intenso, pero había dejado de nevar hacía unas horas, y notó, al observar [...] el inmenso baldío por cuyo borde caminaba, que no se veía el menor rastro de nieve. ${ }^{41}$

13 La aparición de la nieve en esta "ciudad del litoral» nos remite de inmediato a $E l$ Eternauta de Oesterheld, como una cita y un homenaje tanto al texto como al autor desaparecido ${ }^{42}$. Sin duda, puede leerse El Eternauta como un relato de anticipación, una alegoría de los tiempos que vendrán y en este sentido, funciona como el perfecto subtexto de la novela de Gandolfo, escrita cuando ya están transcurriendo esos tiempos en los cuales una de sus víctimas será el autor de la historieta. En la misma atmósfera "irreal », la investigación de La reina de las nieves se hace imposible, todos los encuentros están marcados por la ambigüedad y la sospecha $\mathrm{y}$, como es previsible para el lector, el protagonista no encuentra a la mujer buscada. Sin embargo, otro encuentro, con «la muchacha del tren » entrevista en su viaje a la ciudad, resulta paradójicamente « una de las pocas cosas reales que le habían ocurrido $»^{43}$; es que el sueño que ella le relata, en que se ve como " una especie de reina de las nieves », contiene las claves para despejar la densa y confusa bruma que parece envolver la comprensión de los hechos. La joven se describe «erguida, en un aire gélido [...] de pie sobre la nieve [...] me deslizaba en un bosque espeso [...] sólo oía cosas : gruñidos, garras raspando contra los troncos [...] Noté que tenía las manos blancas como mármol »44.

14 A su vez, la novela remite también al cuento de Hans C. Andersen del mismo nombre que, como la mayoría de los relatos de origen popular, es una metáfora de la lucha entre el 
bien y el mal : el trozo de espejo que se ha clavado en el corazón de uno de los niños protagonistas determina su cambio de conducta, parece convertirlo en alguien con « corazón de hielo », tradicional expresión para hablar de la maldad y la crueldad. Desde el hielo, la nieve y el frío del cuento popular a los de la historieta El Eternauta, desde el mal como principio moral a un mal anclado en lo político, la novela de Gandolfo recorre un camino sesgado para omitir y sugerir al mismo tiempo lo que no se menciona pero está presente todo el tiempo : el horror de la dictadura ${ }^{45}$.

\section{Contar al sesgo con aire de farsa}

Es posible señalar otras « estéticas de lo elusivo » igualmente compartidas por escritores de las dos orillas del Río de la Plata. Un ejemplo interesante lo plantean dos textos en que se recurre por momentos al tono cómico, a la farsa, incluso al grotesco y donde el horror funciona como un telón de fondo amenazante para los personajes, verdaderos perdedores, que oscilan entre lo patético y lo ridículo. Un cuento del argentino Juan Sasturain, «San Jodete, apóstol de la desgracia » ${ }^{46}$, expone a la perfección la trayectoria ejemplar de un antihéroe perdedor. La vida de San Jodete condensa la transformación sufrida desde la conocida figura del fracasado tanguero de la poesía de Discépolo y la mitología popular hasta el perdedor trágico. El cuento lo sigue desde sus canónicos comienzos de cantor de tangos hasta su etapa de predicador que acaba cuando « un falcon verde y sin chapa lo levantó mientras arengaba a los paseantes " y se cierra con su muerte durante «la agonía de la dictadura $»^{47}$. A su vez, este destino de "perdedor político » lo vincula con el protagonista de Manual de perdedores, novela del mismo autor. El personaje es descrito como « una ráfaga que pasó por los diarios de mediados de los setenta [...] junto a sátiros de poca monta o las andanzas de los Falcon color mar turbio $»^{48}$. Su vida entonces corre paralela a la historia argentina, su propuesta se aleja cada vez más del lamento y se politiza, se diferencia así de los derrotados que, según sus palabras, confunden $«$ joderse con resignarse $»^{49}$.

Es decir, a través del protagonista se reconstruye y transforma una tradición que se inicia con la figura del fracasado o frustrado cuyo destino melancólico se cumple inexorablemente y más allá de su voluntad. Los personajes del teatro de Armando Discépolo y del tango son paradigmáticos, en los años ' 30 y ' 40 , de esta actitud existencial de aceptación del fracaso ; lejos de ser una elección política, una estrategia destinada a resistir, su resignación fatalista representa para algunos críticos "una condición nacional » ahistórica. Por el contrario, el antihéroe del cuento de Sasturain evoluciona hacia una figura claramente conectada con una coyuntura histórica que incide en su vida, la transforma y a la cual enfrenta con su proyecto de perdedor «no resignado ». Muchos son los índices de este vínculo entre la Historia y la vida de San Jodete : la muletilla que reitera el personaje (« Hay que joderse, viejo ») cambia (« Hay que joderse, hermano del Sur ») hasta convertirse en consigna (« San Jodete junto a las mayorías nacionales. Patria o Colonia. Hagamos Frente a la Desgracia»). Y estas mutaciones corresponden a momentos bien precisos de los años '70: la muerte de Perón («Ya por entonces la Desgracia, la gran señora, sobrevolaba entre el cielo y la tierra »), la dictadura militar («De regreso una vez más [...] cuando sucedió lo del otoño del $76 »)^{50}$. De forma paralela, el cuento deja atrás el humor del comienzo, cuando la figura " pintoresca » es casi una parodia cómica del costumbrismo tanguero, para transformarse en un relato sobre la 
dictadura, sobre la pérdida, sobre el aprendizaje acerca de cómo vivir derrotado « porque la verdad está en aceptar vivir y pelear con ese cuatro que nos toca $»^{51}$.

Es interesante recordar que este relato se publicó en las colecciones Zenitram y La mujer ducha junto con otros dos, «Zenitram » y «El general Rosca, conquistador de la nada », cuyos protagonistas son también perdedores anclados en circunstancias históricas precisas. En particular «Zenitram » resulta un patético Superman de América del Sur ${ }^{52}$ que invierte desde su mismo nombre (Martínez) la trayectoria victoriosa del personaje norteamericano. Pero la inversión fundamental se refiere a sus hazañas que han transgredido «las reglas impuestas desde el norte »; por eso, el ex héroe y compañero que viene a matarlo le recuerda: "Sabías que no debías involucrarte, meterte con la historia, con la política [...] sabías que no podías hacer política » [la bastardilla es mía] ${ }^{53}$. Decadente y envejecido, Zenitram es, como dice el narrador, «símbolo del Poder Ser Nacional $\aleph^{54}$, un superhéroe argentino que en un futuro no muy lejano representa el desastre al que se ha precipitado el país. Su rebeldía contra esas reglas impuestas por el Norte lo lleva a la muerte, es un fracasado del futuro, cuando ya no parece quedar esperanzas en un Buenos Aires de ciencia ficción en el que se han cumplido los peores pronósticos del presente. A su vez, «El general Rosca... » parodia e invierte al General Roca, héroe del siglo XIX en la historia oficial, que conquistó el « desierto » y masacró las poblaciones aborígenes del sur ${ }^{55}$. La experiencia de Rosca es la contracara del pasado «glorioso » del genocida Roca : como él, intenta conquistar un « desierto » que en este caso es verdaderamente «nada ». Su expedición y su delirante encuentro con los indios en pleno siglo XX se diluyen en el año '30, coincidiendo con el primer golpe militar de la historia argentina. No parece casual entonces que su epopeya haya sido recogida por primera vez, según la versión del narrador, por un periodista yanqui en "South of the border, un detestable ensayo $"^{56}$ lleno de prejuicios. En realidad, "south of the border » vale para los tres cuentos marcados por episodios ligados a los debates políticos en torno a lo nacional: la historia de las últimas décadas define la vida de San Jodete cuyas muletillas, como ya se dijo, incluyen consignas como «Patria o Colonia » y apelan a los " hermanos del Sur ». Si los antihéroes de los dos cuentos ubicados en el pasado y el futuro sufren un desacomodo temporal y pretenden reiterar historias del pasado en un presente al que no parecen pertenecer, "San Jodete » se encuentra ligado a la historia de su tiempo y su lucha coincide con su época. Su vida está sujeta a los avatares políticos de su tiempo, su derrota es la de un proyecto histórico; por eso no se resigna, reivindica hasta el final la capacidad de resistencia a través de múltiples metáforas y culmina en la fundación del Centro de Estudios de la Desgracia, su último intento donde demostrar que " "doler" es verbo intransitivo, aunque haya quien diga lo contrario " $^{57}$ " San Jodete» representa la culminación de una saga notoria en la producción de Sasturain desde Manual de perdedores, probablemente el narrador argentino más interesado en leer la historia de los últimos treinta años con esta inflexión " perdedora ».

Es imposible no asociar "San Jodete» a la novela breve La balada de Johnny Sosa del uruguayo Mario Delgado Aparaín: Johnny es un patético cantante de blues, negro y pobre, cuya mujer era "alguien que se había jugado a vivir con un perdedor ${ }^{58}$. Es también víctima de la manipulación de los «notables del pueblo » que en tiempos de la dictadura quieren obligarlo a transformarse en un cantante « decente » a la medida de sus deseos y «quitarle el ánimo de ser lo que quería ser ${ }^{59}$. El siguiente fragmento podría pertenecer al cuento de Sasturain y recuerda la historia de resistencia de San Jodete: «Johnny llevaba en el entrecejo esa inconfundible actitud de alerta de los que van 
pensando : "Voy, pero a mí no me van a joder". Sin embargo, sin que tuviesen necesidad de decirlo con palabras, lo jodieron $"$.

Su huida a campo traviesa, en el final del relato, es el regreso a la dignidad y la restitución de su identidad, su destino parece ser diferente al del personaje de Sasturain y deja abierto un camino a la esperanza. Ese escape del personaje en busca de la libertad es el punto clave en que difieren los dos textos; en el de Sasturain la muerte cierra toda alternativa, mientras Johnny

se alejaba de Mosquito a campo traviesa sin haber tomado la precaución de averiguar dónde diablos quedaba la frontera [...] se dio el placer de dibujar una sonrisa más bien oscura pensando que por primera vez en su vida, por más que no hubiera esperanza de festejarlo [...] los había jodido, bien, pero bien jodido. ${ }^{61}$

Más allá de esta diferencia, ambos relatos construyen el mismo tipo de antihéroe : alguien que evoluciona de ser un personaje "pintoresco", marginal y degradado (una de las "ventajas » de la adaptación de Johnny al sistema es el regalo de una dentadura postiza hecha por el dentista del ejército), a ser una figura ética cuya decisión se torna en un hecho político.

En ambos textos la dictadura es un telón de fondo, una amenaza de la que poco se habla y sólo bajo la forma de alusiones y comentarios sesgados. Otro relato de Delgado Aparaín extrema la omisión y opta por un "desvío »: Alivio de luto aporta una mirada muy particular sobre el fin de una etapa y los comienzos de una nueva época que surge donde se cruzan el pesimismo con la esperanza. La novela puede leerse como una metáfora de la dictadura o, mejor, del fin de ella. El título alude a un vestido cuyo color está destinado a aliviar el negro del luto y que funciona, otra vez, como una sinécdoque de ese momento inicial de apertura política. Apertura que permite pensar en la posibilidad de dejar atrás el horror, de volver de a poco a «los colores claros » y que, en este sentido, plantea una esperanza en apariencia muy distinta a otros textos de la posdictatura. El vestido que insiste en comprar el protagonista para regalar a la joven, cuya partida en busca de la libertad cierra el relato, es « de organdí con flores estampadas sobre un fondo del color violáceo brillante de los obispos " ${ }^{62}$. Tiene el color del «medio luto ", el que se usa para abandonar el rigor de la ropa negra, el mismo color que tiñe al país : « por los últimos días de 1984, cuando terminaron por cerrarse los eternos, crueles y fanfarrones tiempos del luto, dando paso a regañadientes al alivio ${ }^{63}$. El texto oscila entre la esperanza de « alivio » y el desconsuelo « del calamitoso presente de los derrotados » ${ }^{64}$; en esta tensión debate acerca de las posibilidades de la memoria y de la escritura para recuperar el pasado : la dudosa legitimidad de cualquier reconstrucción, el refugio en la invención a la que aferrarse y desde la cual poder renacer alguna vez.

\section{Narrar el mal, contar al sesgo}

La polémica en torno a la posibilidad de representar el horror parece resolverse de alguna manera en los textos mencionados y obliga a una reconsideración de las relaciones éticas entre lenguaje y violencia. De hecho, autores como Espósito y Onfray, aun a sabiendas de las dificultades que conllevan esas historias, rechazan la idea de indecibilidad. De acuerdo con Esposito, el lenguaje es el objeto mismo de la política y es el lenguaje lo que hace del hombre un ser político, lo que llama la " palabra impolítica » es la que sigue al desastre, la que «lo cuenta sin descanso aun sabiendo que desastre es precisamente lo que no se puede contar [...] La palabra imposibilitada para hablar está sin embargo obligada a 
hacerlo; obligada a decir su propia imposibilidad $»^{65}$. En la misma vía, Onfray reconoce que el nazismo como realidad coloca en dificultades al lenguaje para expresarlo, pero al mismo tiempo se pregunta cómo hacer «para llenar el agujero negro de la memoria » y hacer justicia: «es preciso terminar con el punto muerto de lo indecible y de las experiencias límites para que la política actual y futura sea iluminada por las lecciones que es necesario aprender de la experiencia de los campos de concentración nazis ${ }^{66}$; contar, abandonar la idea de lo irrepresentable, es estonces asumir una responsabilidad ética frente al futuro.

Sin duda, pueden hacerse muchos reparos a la idea de « indecibilidad» 0 « imposibilidad de representar "; las dificultades para resolver este vínculo complejo entre la literatura y el arte en general- y una ética política de la representación, tienen en los análisis sobre el sentido y la posibilidad de narrar « Auschwitz » su punto más extremo por la condición límite del campo y su "inarrabilidad». Auschwitz es entonces el espacio donde se condensan el dilema de representar el horror, el quiebre absoluto de la ley y de la justicia ; espacio que marca el eclipse de la ética y la política y abre un nuevo territorio -el de la excepción, la exclusión y la violencia- que contiene la naturaleza misma del mal. Si representa la forma extrema del horror, si parece sintetizar una clase de mal inédito hasta ese momento -que obliga a repensar el concepto- parece lógico que el arte, la ficción especialmente, intente dar cuenta de él, lo asedie buscando comprenderlo y explicarlo. Los mismos debates que se dan en el campo filosófico y político pueden encontrarse en la literatura: los relatos reiteran las mismas disyuntivas en torno a la posibilidad de su representación. El mal está profundamente enraizado en las condiciones políticas que lo hacen posible y alcanza tal naturaleza que produce el efecto de inaprensible, inenarrable, irrepresentable. Como dice Bernstein, « los campos [...] sirven como laboratorios en los que se verifica la creencia de que todo es posible $»^{67}$. Ese « todo" genera un vacío en torno al cual giran ensayos, ficciones y testimonios, tratando de atraparlo, reducirlo, conjurarlo.

El problema de "narrar el mal » es el problema de hacer presente lo « inimaginable », de dar cuenta de algo que, por su misma naturaleza, parece "escapar» al lenguaje. Esta «herencia» de Auschwitz resurge de formas diversas: representar el horror, "representar Auschwitz», es un tópico que regresa cuando se abordan textos latinoamericanos ligados a experiencias límites. No se trata de asimilar una tragedia a otra, aunque muchas de las reflexiones políticas, éticas y literarias sobre el mal que se proponen para Auschwitz son iluminadoras para el análisis de esta narrativa. Auschwitz no es algo excepcional, es una posibilidad inherente a la condición humana en determinadas circunstancias y en este sentido el cuento de Borges parece, desde la literatura, desde la ficción, sostener esta afirmación. Valeriano Bozal se refiere a la paralización del lenguaje frente a la experiencia traumática del horror con términos como " estupor", «perplejidad", «incredulidad » ${ }^{68}$ que, sin embargo, aún reunidos no parecen aproximarse a lo vivido por las víctimas. El arte y la literatura posteriores al nazismo han estado sometidos a las fuertes presiones de lo que parece no poder ser dicho y ese "estupor» se resuelve muchas veces en una reflexión sobre la condición del lenguaje mismo y en una referencia que llamo «sesgada » a los hechos; es decir, se evita su representación directa. La cuestión de representar de forma explícita o no el horror es un punto clave de los debates y atañe a la cuestión de la forma literaria "adecuada"; « imposibilidad " $\mathrm{y}$ « efectividad » son palabras frecuentes en las discusiones que apuntan 
a la funciones ético-políticas de los discursos y a la perduración en la memoria como forma de la búsqueda de justicia simbólica o real ${ }^{69}$.

Vale la pena citar un texto que desde la primera página nos enfrenta a esa violencia límite e intenta narrarla : en La escritura o la vida, de Jorge Semprún, contar esos hechos vividos y recordados, narrar el mal, resulta el problema recurrente de otra lucha, la de la escritura y sus posibilidades de representar: "cabría pasarse horas testimoniando acerca del horror cotidiano sin llegar a rozar lo esencial de la experiencia del campo. Incluso si se hubiera testimoniado con una precisión absoluta [...] incluso en ese caso podría no acertar en lo esencial $»^{70}$. En verdad, Semprún es una figura clave en el debate acerca de cómo narrar y qué representar por su defensa del uso de la imaginación y de la ficción en el testimonio : « una duda me asalta sobre la posibilidad de contar. No porque la experiencia vivida sea indecible. Ha sido invivible, algo del todo diferente, como se comprende sin dificultad. Algo que no atañe a la forma de un relato posible, sino a su sustancia [...] Únicamente el artificio de un relato dominado conseguirá transmitir parcialmente la verdad del testimonio $»^{71}$. El problema de cómo contar las experiencias límites, en qué orden se organizan los sucesos, será entonces tan importante como el qué contar. Jacques Rancière es quien puede quizá cerrar el debate en la medida en que, en El viraje ético de la estética y la política, rechaza la noción de lo irrepresentable, una categoría que, en su opinión, denota una imposibilidad. El punto clave que puede zanjar la discusión está en que no se trata de pensar en " una imposibilidad de representar » sino en los medios de representación : « el problema no es saber si se puede o se debe o no representar, sino qué se quiere representar y qué modo de representación se elige para ese fin ${ }^{72}$.

Éste es el punto esencial para los relatos que cuentan el horror y la experiencia traumática de las pérdidas; éste es el punto que parecen haber resuelto los textos aquí considerados al optar por una estética sesgada para una política o para una política de la estética : las diferencias en el modo de contar y en la elección de qué se ha elegido contar son las que definen la postura de esta narrativa. Han apelado a nuestra imaginación, decidieron que la violencia debe ser expresada en una forma distinta que a través de la violencia, decidieron que es mejor decir menos de lo que se sabe y dar a entender más de lo que se dice. Pertenecen a una tradición que practica la escritura sesgada, elusiva, y deja al lector imaginar, sabedora de que cuanto más se persigue decirlo todo, más se fuga lo perseguido. Philippe Mesnard señala, a propósito del testimonio, que éste «incluye blancos y silencios [...] pretender hacerle decir todo, reducirlo al contenido, es alterarlo definitivamente ${ }^{73} \mathrm{y}$ recuerda la famosa frase de Wittgenstein al final de su Tractatus logico-philosophicus : " hay que callar sobre aquello de lo que no se puede hablar »; frase que resultó clave para toda una tradición literaria en el Cono Sur, eje de textos como Respiración artificial de Ricardo Piglia ${ }^{74}$. Sin embargo, esta narrativa no calla, en ella la ausencia se hace presencia y elige el trazo oblicuo, la atenuación y el desvío, un camino sesgado para contar, como diría Rancière, nuestra « catástrofe infinita ». 


\section{BIBLIOGRAFÍA}

Amar Sánchez, Ana María, El relato de los hechos. Rodolfo Walsh : testimonio y escritura, $2^{a}$ ed., Buenos Aires, Ediciones de la Flor, 2008.

Amar Sánchez, Ana María, Instrucciones para la derrota. Narrativas éticas y políticas de perdedores, Barcelona, Anthropos, 2010.

Arendt, Hannah, Eichmann en Jerusalén. Un estudio sobre la banalidad del mal, Barcelona, Lumen, 2001.

Bernstein, Richard J., El mal radical. Una indagación filosófica, Buenos Aires, Lilmod, 2004.

Borges, Jorge Luis, « Deutsches requiem », en El Aleph, Buenos Aires, Emecé, 1996.

Bozal, Valeriano, El tiempo del estupor, Madrid, Siruela, 2004.

Cohen, Esther, Los narradores de Auschwitz, México, Fineo, 2006.

Cortázar, Julio, «Graffiti », en Queremos tanto a Glenda, Cuentos completos/2, Buenos Aires, Alfaguara, 1994.

Cortázar, Julio, « Las babas del diablo », en Las armas secretas, Cuentos completos/1, Buenos Aires, Alfaguara, 1994.

Cortázar, Julio, « Segunda vez », en Alguien que anda por ahí, Cuentos completos/2, Buenos Aires, Alfaguara, 1994.

Cortázar, Julio, Rayuela, Buenos Aires, Sudamericana, 1967.

Dávila, María de Lourdes, Desembarcos en el papel. La imagen en la literatura de Julio Cortázar, Rosario, Beatriz Viterbo, 2001.

Delgado Aparaín, Mario, Alivio del luto, Montevideo, Alfaguara, 1998.

Delgado Aparaín, Mario, La balada de Johnny Sosa, Montevideo, Alfaguara, 2000.

Esposito, Roberto, Confines de lo político, Madrid, Trotta, 1996.

Friedlander, Saul, ed., En torno a los límites de la representación, Bernal, Universidad Nacional de Quilmes, 2007.

Gandolfo, Elvio, La reina de las nieves, Buenos Aires, CEAL, 1982.

Gómez López-Quiñones, Antonio, Borges y el nazismo, Granada, Universidad de Granada, 2004.

Kacandes, Irene, « Narrative Aprostrophe : Reading, Rhetoric, Resistance in Michel Butor's La modification and Julio Cortázar's “Grafitti” ", Style, 28 (1994), p. 329-349.

Mate, Reyes, Memoria de Auschwitz, Madrid, Trotta, 2003.

Mesnard, Philippe, Testimonio en resistencia, Buenos Aires, Waldhuter Editores, 2011.

Onfray, Michel, Política del rebelde, Buenos Aires, Perfil, 1999.

Piglia, Ricardo, Formas breves, Buenos Aires, Temas, 1999.

Piglia, Ricardo, Respiración artificial, Buenos Aires, Pomaire, 1980. 
Prego Gadea, Omar, «Función nocturna », en Solo para exiliados, Cuentos completos, Montevideo, Alfaguara, 2000.

Prego Gadea, Omar, Julio Cortázar (la fascinación de las palabras), Montevideo, Ediciones Trilce, 1990.

Rancière, Jacques, El viraje ético de la estética y la política, Santiago, Palinodia, 2005.

Sasturain, Juan, El domicilio de la aventura, Buenos Aires, Ediciones Colihue, 1995.

Sasturain, Juan, La mujer ducha, Buenos Aires, Sudamericana, 2001.

Sasturain, Juan, Manual de perdedores, 1 y 2, Buenos Aires, Legasa, 1985 y 1987, 2 ts. Hay ed. posterior que reúne ambas partes en un solo tomo (Barcelona, Ediciones B, 1998).

Schuster, Cindy, Representaciones de ausencia : intersecciones de memoria y política en la ficción latinoamericana (1965-2005), tesis de doctorado, University of California-Irvine, 2008.

Semprún, Jorge, La escritura o la vida, Barcelona, Tusquets, 1995.

Virilio, Paul, El procedimiento silencio, Buenos Aires, Paidós, 2001.

\section{NOTAS}

1. H. Arendt, Eichmann en Jerusalén. Un estudio sobre la banalidad del mal, Barcelona, Lumen, 2001, p. 382.

2. J. L. Borges, «Deutsches requiem », en El Aleph, Buenos Aires, Emecé, 1996, p. 137.

3. S. Friedlander, «Introducción », en En torno a los límites de la representación (Saúl Friedlander, editor), Bernal, Universidad Nacional de Quilmes, 2007, p. 3.

4. Este trabajo continúa algunas reflexiones sobre representación del horror y la violencia consideradas en mi libro Instrucciones para la derrota. Narrativas éticas y políticas de perdedores, Barcelona, Anthropos, 2010.

5. Borges y el nazismo, Granada, Universidad de Granada, 2004, p. 217. Gómez López-Quiñones sostiene : «No es extraño, por otra parte, que este tipo de acercamiento no fuera entendido correctamente ya que el Holocausto o la "solución final" han recibido un tipo de representación que fomenta la afinidad emocional y catártica con el sufrimiento de las víctimas » (ibid., 136).

6. Op. cit., p. 272.

7. Ibid., p. 140-141.

8. Ibid., p. 130.

9. Ricardo Piglia también ha leído este cuento como un relato de anticipación. Se refiere a él en «El último cuento de Borges » : « La confesión del admirable (del aborrecible) Otto Dietrich zur Linde es en realidad una profecía, quiero decir una descripción anticipada del mundo en que vivimos » (Formas breves, Buenos Aires, Temas, 1999, p. 66). Igualmente, Reyes Mate, en Memoria de Auschwitz (Madrid, Trotta, 2003, p. 131) concuerda con la ficción borgeana : "medio siglo después [...] tenemos que reconocer que la barbarie ha vuelto a repetirse, bien es verdad que bajo otras formas y en otros lugares. La violencia que alumbró el siglo XX, y que tuvo en Auschwitz su punto álgido, no ha cesado de acompañarnos ». Por último, puede citarse a Paul Virilio, quien recuerda que « el arte de este siglo no cesó de anticipar peligrosamente la abominación de la desolación de los tiempos modernos » (El procedimiento silencio, Buenos Aires, Paidós, 2001, p. 52).

10. J. Cortázar, "Graffiti", en Queremos tanto a Glenda, Cuentos completos/2, Buenos Aires, Alfaguara, 1994, p. 396.

11. Loc. cit.

12. Ibid., p. 399. Dejo de lado aquí el análisis del problema de la enunciación en este relato en tanto introduce otras cuestiones teóricas que exceden el tema de este trabajo. Sólo recordaré que 
el cuento parece narrado por un hombre que ve y sigue los trazos hechos por una mujer. En una torsión muy característica en la narrativa de Cortázar, en el párrafo final, el lector se da cuenta que es la mujer quien narra, dialoga e « imagina » a su interlocutor masculino. Cindy Schuster, en «Los intersticios en el muro : imaginando el cómplice en "Graffiti” » (capítulo de su tesis doctoral Representaciones de ausencia: intersecciones de memoria y política en la ficción latinoamericana (1965-2005), University of California-Irvine, 2008), analiza en profundidad los narradores y narratarios en este cuento y señala que « el cuento consiste en lo que ella imaginaba que él imaginaría sobre ella ».

13. Ibid., p. 398.

14. Ibid., p. 399.

15. Ibid., p. 397.

16. Ibid., p. 399.

17. Ibid., p. 400.

18. Sobre la relación de la obra de Cortázar con la imagen, véase el estudio de María de Lourdes Dávila (Desembarcos en el papel. La imagen en la literatura de Julio Cortázar, Rosario, Beatriz Viterbo, 2001) y su análisis de la importancia del «muro de palabras », del grid, descrito por Morelli en Rayuela: «La frase se repite a lo largo de toda la página, dando la impresión de [...] un muro de palabras [...] Pero hacia abajo y a la derecha, en una de las frases falta la palabra lo. Un ojo sensible descubre el hueco entre los ladrillos, la luz que pasa" (Rayuela, Buenos Aires, Sudamericana, 1967, p. 425).

19. Ibid., p. 397.

20. Ibid., p. 398.

21. Ibid., p. 399.

22. Loc. cit.

23. Ibid., p. 400.

24. Ibid., p. 399.

25. Véase el artículo de Irene Kacandes, quien sugiere que el uso de la segunda persona en el discurso narrativo de «Graffiti » funciona a manera de un « apóstrofe narrativo ». La estructura del apóstrofe cuenta con un hablante que se dirige a un destinatario ausente, quien no le puede responder. En «Graffiti », debido a la disponibilidad y la ambigüedad del signo "vos » pronunciado por la narradora, el pronombre podría ser apropiado por cualquier lector, ya que lo invita a sentir que el discurso va dirigido a él («Narrative Aprostrophe: Reading, Rhetoric, Resistance in Michel Butor's La modification and Julio Cortázar's "Grafitti” », Style, 28, 1994, p. 331).

26. Op. cit., p. 497.

27. «Lo que queda por decir es siempre una nube, dos nubes, o largas horas de cielo perfectamente limpio, rectángulo purísimo clavado con alfileres en la pared de mi cuarto » (J. Cortázar, "Las babas del diablo", en Las armas secretas, Cuentos completos/1, Buenos Aires, Alfaguara, 1994, p. 224, apud O. Prego Gadea, Solo para exiliados, Cuentos completos, Montevideo, Alfaguara, 2000, p. 152).

28. «Capaz que entonces las cosas cambiaban y que la hacían salir por otro lado aunque no supiera por dónde ni por qué » (J. Cortázar, «Segunda vez », en Alguien que anda por ahí, Cuentos completos/2, Buenos Aires, Alfaguara, 1994, p. 139, apud O. Prego Gadea, « Función nocturna », en Solo para exiliados, op. cit., p. 162).

29. La perspectiva de la enunciación pasa sin solución de continuidad del torturador a la víctima que se encuentra en una oficina donde muchos han sido citados sin saber qué les espera. La escena remite a $\mathrm{El}$ proceso de Kafka por el espacio burocrático aparentemente inocente y por la ignorancia de las razones para haber sido convocados. La mujer deberá volver otro día y los lectores sabemos que ya no saldrá de allí, el contraste entre su ingenuidad y el «saber» del « funcionario » genera el espacio del horror no dicho: «Antes de irse [...] pensó que el jueves 
tendría que volver. Capaz que entonces las cosas cambiaban y que la hacían salir por otro lado aunque no supiera por dónde ni por qué. Ella no, claro, pero nosotros sí lo sabíamos, nosotros la estaríamos esperando a ella y a los otros, fumando despacito... » (J. Cortázar, « Segunda vez », op. cit., p. 139).

30. O. Prego Gadea, « Función nocturna », op. cit., p. 162.

31. Ibid., p. 165. La primera parte del relato ya está poblado de signos inquietantes que preparan el clima « kafkiano » posterior ; por ejemplo, luego de comparar el movimiento de los patrulleros al de un hormiguero, el narrador mira las manos blancas del personaje Julio Cortázar e imagina que « por un instante quedaron cubiertas de furiosas hormigas mordiendo la carne » (ibid., 164). También cabe imaginar aquí una alusión a una famosa imagen de Un perro andaluz de Luis Buñuel.

32. Ibid., p. 166.

33. Ibid., p. 167.

34. Ibid., p. 168.

35. Ibid., p. 167.

36. Ibid., p. 169.

37. Cortázar ha comentado a propósito de « Graffiti » en una entrevista con Prego Gadea que « el horror se acentúa porque se vuelve una especie de latencia omnímoda, una atmósfera que flota, en donde no se pueden conocer caras ni responsabilidades directas » (O. Prego Gadea, Julio Cortázar (la fascinación de las palabras), Montevideo, Trilce, 1990, p. 188).

38. Me he ocupado de esta particular condición política del género policial en Latinoamérica en mis trabajos. El relato de los hechos. Rodolfo Walsh : testimonio y escritura, Buenos Aires, Ediciones de la Flor, 2008 [segunda edición] y en el segundo capítulo de Juegos de seducción y traición. Literatura y cultura de masas, Rosario, Beatriz Viterbo, 2000.

39. El primer indicio "anómalo» lo da el ex patrón al explicar el motivo de la búsqueda: «Porque comprenderá que con la nueva situación no podemos quedarnos en el país, y quisiera que ella viniera con nosotros, o al menos verla antes de partir » (E. Gandolfo, La reina de las nieves, Buenos Aires, CEAL, 1982, p. 15).

40. Ibid., p. 19. El relato insiste: «la niebla cubría las calles, las casas y las personas durante meses. Los libros se pudrían en los anaqueles... » (p.21); « las ráfagas eran doblemente frías y fuertes en los descampados que rodeaban el monoblock» (ibid., p. 70). Si bien no se menciona nunca el nombre de la ciudad, en el prólogo a una edición posterior, de 1998, Gandolfo afirma que se trata de Rosario.

41. Ibid., p. 64, 70 y 72 respectivamente.

42. El Eternauta se publicó entre 1957 y 1959. Hubo una nueva versión realizada por Alberto Breccia en 1969 ; hay una secuela, El Eternauta II, con dibujos del ilustrador original, Francisco Solano López, publicada en 1976-77. Cabe recordar que El Eternauta tiene como héroe a Juan Salvo y empieza en una fría noche de invierno en su casa en los alrededores de Buenos Aires cuando se escucha en la radio una extraña noticia respecto de una explosión en el Océano Pacífico. Se nota un inusual silencio en la calle, y al mirar por la ventana los personales descubren que la ciudad está cubierta por una especie de nieve que cae en copos desde el cielo; también distinguen varios cadáveres de transeúntes y descubren que el contacto con la nieve provoca la muerte instantánea. Pronto encuentran las primeras señales de que la nevada es producto de una invasión extraterrestre; Salvo entonces junto con otros amigos y sobrevivientes se unirán a la resistencia. El relato es una clara metáfora política, por ejemplo, los cascos de los invasores en los dibujos de Solano López remiten claramente a los usados por los nazis.

43. Op. cit., p. 80.

44. Ibid., p. 77.

45. Muchos de sus cuentos siguen similares estrategias: en "Ferrocarriles Argentinos» de la colección del mismo nombre un viaje en tren resume el terror, la impotencia, la arbitrariedad de 
la dictadura y funciona como una sinécdoque de la misma. El relato, que comparte iniciales con «Fuerzas Armadas », narra un suceso del que es testigo el protagonista, una anécdota simple en que por haberse equivocado de tren una mujer con un niño es obligada a bajarse y quedar sola en medio de la noche en un andén abandonado. Sin embargo, todo el episodio -la llegada de los inspectores, la falta de energía para impedir « la decisión final », la resignación de los pasajerosse convierte en una historia « sumergida, inexplicable [...] perdida e intraducible [...] como tantas otras cosas de aquella época » (166).

46. Publicado en el volumen de cuentos Zenitram (1996) y reeditado en La mujer ducha (Buenos Aires, Sudamericana, 2001). Me he referido en particular a este personaje en mi estudio Instrucciones para la derrota, op. cit.

47. J. Sasturain, La mujer ducha, Buenos Aires, Sudamericana, 2001, p. 90-91.

48. J. Sasturain, Manual de perdedores, Buenos Aires, Legasa, 1985, t. 1, p 12. El Falcon verde mar ha quedado en el imaginario cultural argentino como sinécdoque de la última dictadura y de su sangrienta represión porque ésos eran los autos, por lo general sin chapa identificatoria, con los que «los grupos de tareas» realizaban los secuestros y desapariciones. En esta última cita, el adjetivo « turbio » alude tanto al color como a lo que ocurría en ellos.

49. La mujer ducha, op. cit. p. 104.

50. La vida del personaje está bien pautada por distintas etapas de la historia política argentina del siglo XX e incluye su muerte, ocurrida cuando « la agonía de la dictadura empujaba hacia la desventurada aventura de Malvinas » (ibid., p. 91).

51. Ibid., p. 95. La presencia del humor es un rasgo constante en Sasturain, en sus novelas y cuentos. Cabe aquí citar un comentario de Günter Grass a propósito de la falta de humor en La miseria del mundo de Pierre Bourdieu. El comentario es recogido por Roger Bartra en su libro Territorios del terror y la otredad (Valencia, Pre-textos, 2007, p. 33) : « persiste la capacidad humana para presentarse como figura cómica y, en este sentido, victoriosa, a pesar del dolor y del fracaso. El olvido de cómo reír a pesar del dolor, es una señal de los tropiezos de la Ilustración. Por el camino, hemos perdido la risa triunfante de los derrotados ".

52. Es evidente que los precursores de los antihéroes de Sasturain se encuentran también en las historietas de Héctor Oesterheld. Hay que recordar que la historieta, sobre todo en la Argentina, es otro género en el que se puede ver el vínculo entre gráfica y narrativa en el desarrollo de estas figuras antiheroicas. La revista Fierro, nacida en los comienzos de la democracia, en 1984, dirigida en sus primeros años por Juan Sasturain, fue un espacio clave para este contacto entre imagen y lenguaje con historietas construidas a partir de textos literarios o referidas a la historia reciente como La Argentina en pedazos, La batalla de las Malvinas o Sudor sudaca. La figura que había iniciado esta tradición fue sin duda Héctor Oesterheld : El Eternauta marca un hito, un punto de inflexión clave en el desarrollo del género y en el modo de concebir la aventura, pero fundamentalmente propone un héroe diferente y un nuevo tipo de aventura: "para Oesterheld la acción -ante el peligro y la inminencia de la violencia- es la decisión personal de perder-se [...] la aventura interior recorre un itinerario cuyo sentido es habitualmente contrario al de la aventura exterior. Los conceptos de victoria y derrota se trastruecan ", señala Sasturain en su estudio sobre la historieta El domicilio de la aventura (Buenos Aires, Ediciones Colihue, 1995, p. 123).

53. Ibid., p. 232.

54. Ibid., p. 223.

55. Rosca, según especula el mismo narrador, puede ser una combinación de Rosas, jefe de la primera expedición al « desierto », y de Roca, jefe de la segunda. Sin embargo, Rosca parece ser una ridícula versión de este último, al menos tal como ha quedado fijado en los triunfalistas relatos de la historia oficial.

56. Ibid., p. 45.

57. Ibid., p. 107.

58. M. Delgado Aparaín, La balada de Johnny Sosa, Montevideo, Alfaguara, 2000, p. 62. 
59. Ibid., p. 66.

60. Loc. cit.

61. Ibid., p. 126.

62. M. Delgado Aparaín, Alivio del luto, Montevideo, Alfaguara, 1998, p. 129.

63. Ibid., p. 194.

64. Ibid., p. 134.

65. R. Esposito, Confines de lo político, Madrid, Trotta, 1996, p. 146.

66. M. Onfray, Política del rebelde, Buenos Aires, Perfil, 1999, p. 30-31.

67. R. J. Bernstein, El mal radical. Una indagación filosófica, Buenos Aires, Lilmod, 2004, p. 323.

68. V. Bozal, El tiempo del estupor, Madrid, Siruela, 2004.

69. En este sentido son interesantes los comentarios de Primo Levi : " no había necesidad de subrayar el horror. El horror estaba ahí. No era necesario escribir "esto es horrible" » (citado por Esther Cohen en Los narradores de Auschwitz, México, Fineo, 2006, p. 27).

70. J. Semprún, La escritura o la vida, Barcelona, Tusquets, 1995, p. 103.

71. Ibid., p. 25.

72. J. Rancière, El viraje ético de la estética y la política, Santiago, Palinodia, 2005, p. 41.

73. Ph. Mesnard, Testimonio en resistencia, Buenos Aires, Waldhuter, 2011, p. 439.

74. La novela de Piglia se ha leído como el relato paradigmático -uno de los primeros- sobre la última dictadura argentina ; sin embargo, jamás se la nombra. El texto trabaja la omisión, la alusión, el distanciamiento, para hablar continuamente de «aquello de lo que no se puede hablar ». Sigue aquí Piglia (al igual que muchos autores del Río de la Plata) las enseñanzas de Borges : en «El jardín de senderos que se bifurcan», el narrador nos recuerda que "omitir siempre una palabra, recurrir a metáforas ineptas o perífrasis evidentes, es quizá el modo más enfático de indicarla » (Obras completas, Buenos Aires, Emecé, 1974, p. 475).

\section{RESÚMENES}

El artículo analiza el estrecho diálogo que sostienen la literatura argentina y uruguaya en torno al debate sobre cuál es la "forma adecuada " y más efectiva de narrar el mal, el horror y la violencia extrema, un problema donde el nexo entre ética, estética y política resulta esencial. A partir del cuento «Deutsches requiem» de jorge Luis Borges -considerándolo como un texto fundante para una estética que hace de lo elusivo su principio constructivo-, el artículo trabaja los relatos de Julio Cortázar y el uruguayo Omar Prego Gadea, posiblemente el autor más cercano a Cortázar en la narrativa del Cono Sur y el que sin duda más lo ha homenajeado. Se analizan en especial las relaciones entre « Grafitti », cuento de Cortázar incluido en Queremos tanto a Glenda, y «Función nocturna » de Prego Gadea, perteneciente a su colección Sólo para exiliados. Colección en la que las alusiones, los épigrafes y la misma presencia de Cortázar como personaje, señalan la cercanía estética y política entre ambos. El artículo también considera la producción de otros autores como Elvio Gandolfo (La reina de las nieves y Ferrocarriles Argentinos), en quien es posible ver cómo resuena el mismo modo de referencia « sesgada » y las mismas estrategias que evitan la representación explícita de los hechos encontradas en Cortázar y Prego Gadea.

L'article analyse le dialogue étroit qu'ont maintenu les littératures argentine et uruguayenne autour du débat sur quelle serait la forme la plus adéquate et efficace de narrer le mal, l'horreur et la violence extrême, un sujet problématique où l'articulation entre éthique, esthétique et 
politique est essentielle. En partant du conte «Deutsches requiem » de Jorge Luis Borges texte fondateur d'une esthétique dont l'élision textuelle est le principe constructif, l'article étudie les récits de Julio Cortázar et de l'Uruguayen Omar Prego Gadea, probablement l'auteur le plus proche de Cortázar dans la prose narrative du Cône Sud et sans doute celui qui lui a le plus rendu hommage. Ce sont les relations entre "Grafitti », conte de Cortázar publié dans Queremos tanto a Glenda, et «Función nocturna » de Prego Gadea, publié dans le volume Sólo para exiliados qui sont au cœur de cette analyse. Dans ce volume de contes, les allusions, les épigraphes et la présence de Cortázar comme personnage, montrent leur rapprochement esthétique et politique. L'article considère également la production d'autres écrivains comme Elvio Gandolfo (La reina de las nieves et Ferrocarriles Argentinos), chez qui il est possible de saisir cette même manière «biaisée » de raconter ainsi que les stratégies évitant la représentation explicite des faits présentes chez Cortázar et Prego Gadea.

The article analyzes the close dialogue between Argentine and Uruguayan literature as to the most appropriate and effective way to narrate evil, horror and extreme violence, a question that lies at the very nexus between ethics, aesthetics and politics. Taking the short story « Deutches requiem » by Borges as a foundational text of an aesthetic that makes elusiveness its constructive principle, the essay then examines the stories of Julio Cortázar and the Uruguayan Omar Prego Gadea, who may be the closest Southern Cone writer to Cortázar and the one to most honor Cortázar in his own work. The article analyzes in particular the relationship between "Grafitti » [«Graffiti »], a Cortázar short story included in Queremos tanto a Glenda [We Love Glenda So Much] and «Función nocturna » [ Nocturnal Function»], a Prego Gadea story published in Sólo para exiliados [For Exiles Only]. The latter collection features allusions to and epigraphs from Cortázar's work, as well as the presence of Cortázar as a character, all of which signal the two writers' aesthetic and political closeness. The article also considers the production of authors such as Elvio Gandolfo (La reina de las nieves [The Snow Queen] and Ferrocarriles Argentinos [Argentine Railroads]), in whose works resonate the same "slanted " mode of reference and strategies of avoidance of explicit representation of facts that are characteristic of Cortázar and Prego Gadea.

\section{ÍNDICE}

Mots-clés: représentation, dictature, violence, politique, esthétique

Palabras claves: representación, dictadura, violencia, política, estética

Keywords: representation, dictatorship, violence, politics, aesthetics

\section{AUTOR}

ANA MARÍA AMAR SÁNCHEZ

University of California-Irvine 